\title{
Mulemba
}

Revista Angolana de Ciências Sociais

6 (12) | 2016

Sobre a sociedade e a cultura em Angola e alhures:

algumas reflexões de percepções sobre a realidade e múltiplas experiências

\section{Os limites sociais do crescimento nas sociedades avançadas, uma obra de Fred Hirsch}

\section{Cesaltina Abreu}

\section{(2) OpenEdition \\ Journals}

\section{Edição electrónica}

URL: http://journals.openedition.org/mulemba/1202

DOI: 10.4000/mulemba.1202

ISSN: 2520-0305

\section{Editora}

Edições Pedago

Edição impressa

Data de publição: 1 novembro 2016

Paginação: 319-336

ISSN: 2182-6471

Refêrencia eletrónica

Cesaltina Abreu, «Os limites sociais do crescimento nas sociedades avançadas, uma obra de Fred Hirsch», Mulemba [Online], 6 (12) | 2016, posto online no dia 30 setembro 2018, consultado o 26 janeiro 2021. URL: http://journals.openedition.org/mulemba/1202 ; DOI: https://doi.org/10.4000/ mulemba.1202 


\title{
Os limites sociais do crescimento nas sociedades avançadas, uma obra de Fred Hirsch*
}

\author{
Cesaltina Abreu**
}

O Prefácio do representante da instituição financiadora do livro, destaca os seus principais objectivos: estudar o desenvolvimento das economias mais avançadas e os problemas sociais criados pelo crescimento económico nas democracias do hemisfério norte, bem como as consequências por ele classificadas de desconcertantes, do bem-estar económico.

O Prefácio do Autor refere que o livro propõe-se demonstrar a relação existente entre os impasses de economias avançadas e uma perspectiva considerada antiquada acerca da natureza do crescimento económico e, por decorrência, das suas possibilidades de responder a uma crescente demanda por um número cada vez maior de pessoas.

Na Introdução, o Autor delimita o âmbito do seu trabalho: economias avançadas, década de setenta, uma visão economicista e três questões principais - o paradoxo da afluência, a compulsão

Recensão à obra de Fred Hirsch, Social limits to growth. Prefácio de Tibor Scitovsky. Londres, Routledge, 1978 (2. a edição), 228p.

** Socióloga, Professora Auxiliar e Chefe do Departamento de Sociologia da Faculdade de Ciências Sociais (FCS) da Universidade Agostinho Neto (UAN) e docente convidada do Curso de Mestrado em Ordenamento e planeamento de áreas urbanas do Departamento de Arquitectura da Faculdade de Engenharia da UAN. 
distributiva e o colectivismo relutante, tratados em 13 capítulos organizados em quatro partes.

A tese defendida pelo Autor é de que aquelas questões estão relacionadas entre si e nascem de uma fonte comum, atribuível à natureza do crescimento económico em sociedades em que a grande maioria da população já não se encontra numa fase de consumo de sobrevivência, o que conduz à necessidade de interligar as questões da produção, do abastecimento individual e colectivo, e da distribuição.

Para Hirsch a característica estrutural do moderno crescimento económico reside no aspecto social do consumo, ou seja, crescendo o consumo médio individual, uma parte crescente do consumo adquire um carácter social: à medida que cresce o grau de satisfação individual de consumo de bens e serviços, aumenta a dependência individual, para esse alcance do consumo de todos os outros. $\mathrm{O}$ elemento social do consumo resulta do facto de ele não ser um bem exclusivamente privado nem exclusivamente público, havendo uma relação entre o usufruto de um bem ou produto e as condições em que ele pode ser usado, o que, segundo Hirsch se aplica desde o bem «educação» à posse do produto «carro» ou «casa»: as condições de uso tendem a agravar-se à medida que esse uso se generaliza.

Partindo do exemplo físico do engarrafamento no trânsito, Hirsch considera que o congestionamento social que se verifica nas sociedades avançadas está se tornando um fenómeno amplo, constituindo uma faceta da escassez social, no sentido de que as coisas boas da vida têm limitações na sua produção e no seu uso. A capacidade de absorção do ambiente social condiciona o uso, através da imposição de limites ao consumo, que não dependem do produto ou bem em si, mas das condições do seu uso, ou seja, ao contrário da perspectiva que receava os limites físicos, mais ou menos remotos, existem limites sociais ao crescimento, que resultam do excesso de 320 demanda de bens ou serviços de carácter público, através do sistema político ou dos mecanismos de mercado, uma vez alcançado um patamar aceitável na satisfação da demanda por bens privados.

O processo através do qual cada indivíduo procura satisfazer as suas demandas, altera as condições de outros que buscam, igualmente, a satisfação das suas preferências, o que deve ser visto como um hiato entre oportunidades individuais e sociais, em resultado, por exemplo, da competição por um lugar no mercado de trabalho. A competição individual no mercado de trabalho encerra custos 
ocultos para os demais agentes, que representam um peso morto para a economia e um desperdício social, pelo que se torna importante criar alternativas de distribuição que não visem apenas a resposta à demanda individual, mas que também se inscrevam numa perspectiva mais ampla da interacção social.

Recorrendo ao exemplo da educação, Hirsch discute a questão da demanda endereçada ao Estado por igualdade de oportunidades, na expectativa de uma decorrente igualdade de resultados, o que não se torna viável devido à desigualdade de condições ou pontos de partida, para além das diferenças introduzidas pelo critério selectivo do processo de avaliação do sistema educacional. A partir deste exemplo fica mais fácil compreender o foco de Hirsch na questão da interacção: avaliando a qualidade da instrução de um indivíduo, ele recorre a duas dimensões, uma absoluta e dependente da aplicação e aproveitamento do aluno, da qualidade dos mestres e das condições de ensino, entre outras, e outra relativa, que depende do nível educacional alcançado por outros alunos. Por um lado, o processo de avaliação produz uma selecção entre os alunos, classificando-os em dois grupos, os mais aptos e os menos aptos, e posicionando-os numa escala em função dos seus resultados individuais; por outro lado, as oportunidades não são abertas a todos. Isto significa que nem todas as reivindicações pessoais são satisfeitas e que, no conjunto, o colectivo recebe um produto que não pediu e que se traduz em desperdício social: no primeiro caso, porque o factor determinante para a possibilidade de acesso é a posição do indivíduo na escala de capacidade aquisitiva, e no segundo caso, o desperdício gerado provoca perdas, reduzindo o volume geral da oferta para todos.

O problema da distribuição em decorrência do processo de crescimento resulta, assim, de um desperdício social e da hierarquização funcional da escala aquisitiva, que privilegia os mais bem posicionados e limita o acesso a bens e produtos aos que se encontram nas posições inferiores dessa escala, que terão acesso apenas em função de uma elevação geral da escala. Para o Autor, isto representa o inverso do que se espera, ou seja, à medida que o crescimento económico generaliza o consumo em massa, dá origem a um congestionamento social que privilegia quem se encontra no topo da escala, tornando-se distante a esperança de que todos, principalmente os da parte inferior da tabela, se beneficiem desse aumento do crescimento; estes, pelo contrário, serão sujeitos a uma pressão social ainda maior. 
Segundo Hirsch importa avaliar o que as pessoas têm e a satisfação que isso lhes provoca, sem se preocupar com análises subjectivas: num quadro de escassez crescente, o que as pessoas têm depende da sua posição relativa na hierarquia económica. O processo de crescimento, quando continuado e generalizado, não cumpre plenamente as suas promessas e leva à escassez social que conduz à compulsão distributiva, ou seja, uma demanda por uma mais ampla distribuição do bem-estar que, por sua vez, conduz ao colectivismo relutante, uma vez que a continuação do processo de crescimento parece necessitar de novas condições morais prévias, na medida em que o seu próprio êxito provocou uma erosão na base moral anterior, devido aos efeitos da sua ética individualista.

Considerando que a avaliação do crescimento se faz predominantemente com base na produção económica, Hirsch considera que as tentativas de acrescentar indicadores sociais para conseguir uma avaliação mais realista do rendimento, estão longe de conseguir resultados satisfatórios, devido à dificuldade de construir um índice de desempenho social sistematizado. ${ }^{1}$ Esta constatação do Autor pretende recordar que a proposta keynesiana visava incluir a preocupação com o lazer e condições de trabalho mais satisfatórias, por exemplo, na organização da vida económica e social, o que não foi considerado na implementação da estratégia que uniu a intervenção de mecanismos redistributivos, através de políticas sociais, aos mecanismos naturais do mercado.

Com este livro, o Autor pretende cobrir uma negligência dos economistas em geral: como traduzir uma melhoria económica individual em progresso colectivo sem dar origem a frustrações que resultam da geração de expectativas que não podem ser atendidas. Em contrapartida, alguma contenção no consumo, alcançada por via do rebaixamento do nível de expectativas e do alteamento do nível de desempenho, poderia resultar num processo de acumula322 ção que, ao cabo de um tempo, permitiria uma maior distribuição.

1 O IDH - Índice de Desenvolvimento Humano - foi criado em 1990 por uma equipa de economistas coordenada por Mahbub ul Haq, mas só em 1993 (15 anos após a publicação do livro de Hirsch) a contribuição dos quadros analíticos das capacidades e funcionamentos de Amartya Sen criou o quadro conceptual dessa medida que se proprõe, desde então, avaliar o desenvolvimento não só pelos avanços económicos, mas também pelas melhorias no bem-estar humano. O IDH vem sendo usado desde então pelo Programa das Nações Unidas para o Desenvolvimento (PNUD) para a elaboração do relatório anual. 
Isto pressupõe uma mudança de atitude por parte do público e das instituições que, a seu ver, inflaccionam as demandas económicas, como os sindicatos: a possibilidade de parar os ciclos de consumo reside na incorporação da cooperação social através de mecanismos que conduzam a uma coordenação de objectivos para uma abordagem colectiva.

A orientação de que o indivíduo necessita para formular e priorizar as suas preferências e o alcance de uma visão colectiva, podem ser facilitadas por um correcto diagnóstico das potencialidades e dos constrangimentos que caracterizam um dado momento de uma sociedade. A proposta de Hirsch é de que seja feito esse diagnóstico, reconhecida a natureza do problema e que haja transparência na indicação dos limites impostos às escolhas e dos custos implicados. As formas práticas de conseguir estes objectivos passam pela extensão da participação e pelo papel complementar e compensatório de políticas públicas concebidas numa perspectiva redistributiva; deste modo, seria possível agregar ao princípio do interesse privado um princípio social, reduzindo a tensão estrutural sobre o sistema político e o mecanismo de mercado.

A base teórica dominante no sistema económico construída após a grande recessão nos Estados Unidos, tem como ponto crítico a política de estabilização interna visando o controlo fiscal; esta estabilização teve, como primeira preocupação, minimizar as oscilações da actividade económica, procurando evitar o desemprego e manter a taxa de inflacção sob controlo. O seu segundo objectivo era o de promover a distribuição do rendimento numa perspectiva de crescimento a longo prazo. Esta política desenvolveu-se nas sociedades ocidentais inspirada nos postulados de John Maynard Keynes ${ }^{2}$ que defendia o controlo fiscal como forma de alcançar a estabilização interna a partir da contenção das despesas e o aumento do emprego através do investimento público.

Segundo o Autor, a forma como a teoria keynesiana foi aplicada maximizou a perspectiva consumista realçando que, ainda assim, o foco do consumo como sujeito e objecto do crescimento económico não incorporou qualquer preocupação em relação ao conteúdo

2 John Maynard Keynes, A treatise on money. London, Palgrave Macmillan, 1935; The General Theory of Employment, Interest and Money. Londres, Palgrave Macmillan, 1936; Chapter 2: «The postulates of the Classical Economics». 
desse consumo, deixando este aspecto ao sabor das escolhas que melhor respondessem às preferências do consumidor.

Entretanto, reconhecidas falhas ou imperfeições do mercado relacionadas com a sua incapacidade em responder à demanda de bens públicos ou colectivos - sequer demonstrando perceber tais demandas -, e com os mecanismos de transmissão das preferências dos consumidores aos produtores, via mercado, recebem como resposta-padrão da maior parte dos economistas a indicação de que o crescimento da economia aumentará a capacidade de resposta a tais demandas de consumo individual e colectivo, embora do ponto de vista da implementação não se tenham conseguido remover os impedimentos ao funcionamento pleno e amplo dos mecanismos de mercado, nem encontrar o ponto de equilíbrio, quer no grau de desigualdade óptimo numa dada sociedade quer no nível de intervenção do Estado através das políticas de investimento público. Este aspecto é percebido na insuficiente resposta às demandas de serviços públicos de transportes, de saneamento básico, de segurança pública, entre outros.

Segundo o Autor, o dilema que se coloca ao sistema político e ao mercado no atendimento deste tipo de demandas é devido a que, apesar de o mercado proporcionar diversas escolhas entre ajustes possíveis, não fornece nenhum meio de selecção entre estados alternativos; o sistema político, por seu lado, não conseguiu desenvolver um mecanismo que seja sensível ao tratamento desta questão, o que conduz ao não cumprimento, por ambos, do que o público considera como promessa.

Este quadro de limitações leva Hisch a considerar que o mais importante é tentar perceber se a expansão do consumo não seria possível num quadro hipotético do qual tivessem sido removidas as questões técnicas que respondem pelas falhas e imperfeições do mercado, uma vez que este é um problema que não se colocava na interpretação tradicional da economia.

Considerando a importância da elasticidade da oferta e de substituição para o crescimento e a distribuição no longo prazo, o Autor realiza uma viagem no tempo e analisa as teorias relacionadas com a escassez, desde a limitação física dos recursos naturais (terra, por exemplo) à escassez de recursos sociais (resultante da posição na escala aquisitiva): a ciência e a tecnologia desenvolveram técnicas e práticas que não só aumentaram a produtividade, mas também 
forneceram alternativas aceitáveis, derrubando as expectativas pessimistas das teorias sobre limitação física e exaustão do sistema de produção. Relativamente às teorias da escassez dos recursos sociais, a economia e a política ainda não encontraram respostas, uma vez que a um aumento da disponibilidade física dos bens ou serviços não corresponde um aumento proporcional de satisfação por parte de público. Neste caso específico de escassez, os limites na oferta absoluta de bens ou serviços resultam de padrões de qualidade, relacionados com símbolos de status social, com preferências temporárias (moda) ou com relações de trabalho; o carácter regular deste tipo de escassez económica socialmente gerada permite considerar que a disponibilidade de hoje pode ser maior amanhã devido ao aumento da produção, e que os seus limites poderão ser mais amplos, mas continuará a haver limites.

Introduzindo Harrod, ${ }^{3}$ por ele considerado o fundador da moderna ciência económica do crescimento, Hirsch destaca que ele foi um dos primeiros a observar o que o crescimento não podia realizar: a comparação dos tipos de consumo disponíveis para todos, com os tipos de consumo ao alcance de apenas uma minoria bem posicionada, mesmo em presença de elevados níveis de produtividade, levaria a considerar que os níveis de saciedade económica da sociedade como um todo são sempre inferiores aos níveis correspondentes das classes mais ricas, e que esse aumento de crescimento, por mais prolongado e continuado que seja, não permitiria satisfazer necessidades económicas, valores culturais ou espirituais, enfim, a demanda de bem-estar. As suas conclusões levam Hirsch a considerar que o conceito de crescimento económico, porque muito limitado, não corresponde ao que a teoria económica sugere.

Harrod considerava riqueza democrática o controlo, por todos, dos recursos existentes num dado momento numa certa sociedade, representando a saciedade passível de ser satisfeita, enquanto

3 Roy F. Harrod [1900-1978] desenvolveu concepções teóricas que enfatizavam uma análise dinâmica a partir do instrumental teórico de Keynes, com quem manteve correspondência durante décadas, com inspirações e críticas de parte a parte. As principais obras são: «Doctrines of imperfect competition», The Quarterly Journal of Economics, pp. 442-470, May 1934; The trade cycle. An essay. Oxford, Clarendon Press, 1936; "An essay in dynamic theory: the 1938 draft», edited by Daniele Besomi, History of Political Economy, vol. 28, n. ${ }^{\circ}$ 2, 1996; «An essay in dynamic theory», The Economic Journal, March 1939. 
riqueza oligárquica compreendia o controlo do trabalho de outrem além do próprio, e o acesso a uma parcela mais do que proporcional de bens e serviços escassos em sentido absoluto, considerando haver entre elas uma distância insuperável. Referindo que Harrod não deu sequência à análise deste processo de alcance da riqueza democrática, Hirsch sugere que a combinação de um potencial crescente desta e um potencial estáctico da outra, a oligárquica, produziria um paradoxo: mais riqueza ao alcance de todos significaria maior disputa pelo tipo de riqueza ao alcance de apenas muito poucos.

Os conceitos de «economia material» e de «economia posicional», introduzidos por Hirsch, têm como base os conceitos de «riqueza democrática» e de «riqueza oligárquica» de Harrod e, segundo o Autor, o processo de interacção entre a economia material em crescimento e uma economia posicional que se mantivesse estacionária teria consequências no crescimento económico, na relação crescimento/distribuição dos recursos, e no grau de satisfação das expectativas dos indivíduos.

Embora o Autor tenha abordado as questões que inicialmente colocou de uma forma exaustiva, recorrendo frequentemente a «viagens» à história da fundação do sistema capitalista e a sua associação com a política liberal em estados democráticos emergentes, parece que o objecto da análise centra-se no papel da escassez social na imposição de limites ao crescimento da economia em sociedades avançadas, apontando para a necessidade de adequação do sistema de produção ao sistema de distribuição, numa perspectiva em que as instituições ganhem um novo alento na promoção da produção, melhorem a sua intervenção no sistema de distribuição, e mantenham o seu poder de regulação.

Na perspectiva do Autor, o grande aumento da produtividade material arrastou as fronteiras da procura em massa para áreas onde já não é possível garantir mais oferta a todos, uma situação 326 onde o ganho de um significa perda para outro, com possibilidades de ambos perderem nessa luta. Na busca de compreensão para as razões deste fracasso do crescimento continuado em economias regidas pela associação entre democracia e capitalismo liberal, Hirsch considera que a ausência de um respaldo moral de origem social para o estabelecimento de metas económicas privadas e individualistas por empresas, consumidores e trabalhadores em geral na sua relação com o mercado, permite um comportamento cada vez mais distante da ética social estruturada em torno de perspectivas 
comunais, anterior à expansão do sistema capitalista e da industrialização apoiada na tecnologia, é uma das razões desse fracasso.

Para ele, o legado moral que serviu de suporte à fase inicial do capitalismo liberal não resistiu à agressividade da competição resultante do seu desenvolvimento e ao predomínio crescente do comportamento individualista visando vantagens pessoais, permitindo que, no processo de escolhas, os indivíduos cada vez mais isolados, perdessem o apoio de um conjunto de valores tradicionais. A conjunção destes dois problemas originou dificuldades crescentes no controlo indirecto do sistema, o qual teve o seu funcionamento afectado pelas tensões criadas pela pressão de grupos de interesse e actividades colectivas, tendo como resultado o aumento do desemprego e da taxa de inflacção.

Hirsch defende a necessidade de descobrir uma forma de garantir uma distribuição ética, que passe pela resolução da causa das pressões sobre a escassez social, pois esta aumenta a intensidade da luta distributiva de cada indivíduo e aumenta o seu custo para o conjunto dos indivíduos de uma sociedade.

Esta causa parece remeter à criação do Estado bem-estar, de inspiração keynesiana, em que aos mecanismos de mercado do sistema capitalista se associaram regulamentações estatais e controlos sociais diversos, num ambiente político liberal. A estratégia de impôr limites e dar orientação a uma economia capitalista para retirar dela o melhor e evitar o pior através de mecanismos de redistribuição, pressupunha que as acções motivadas individualmente tivessem consequências sociais benéficas, o que aconteceu na fase inicial de expansão do sistema capitalista. Contudo, a concepção desta estratégia não teve em conta a evolução do sistema e a redução significativa do suporte da moral tradicional pré-capitalista devido à predominância crescente dos critérios do cálculo individualista: as fronteiras em expansão deparavamse com os limites definidos pelos bens posicionais, a ausência de regras para a defesa do bem-comum num ambiente dominado pela perspectiva do bem privado, que os administradores do sistema seriam orientados por motivos mais elevados do que a maximização de seus próprios interesses e que os padrões de comportamento social evoluiriam no sentido de não mais eleger o lucro monetário como bem último, o que faria supôr uma intervenção mínima do Estado no sistema, não só desejável como necessária, na medida em que a acção colectiva criaria mecanismos 
de cooperação, envolvendo todos os interessados, e mecanismos estatais de coordenação.

A solução parece residir numa alteração do padrão de comportamento individual numa perspectiva em que, não deixando que o interesse pessoal continue sendo a motivação das acções pessoais, estas sejam condicionadas pelo interesse social, ou seja, torna-se necessária a mudança da ética social prevalecente. Hirsch considera que esta mudança levará tempo a tomar corpo, porque a dependência mútua entre a moral social existente e os meios para a alterar dificultam a resolução rápida das tensões criadas. Ele defende o diagnóstico e o reconhecimento da necessidade de uma mudança no ambiente de aplicação dos mecanismos existentes, e de medidas para a superação, a mais longo prazo, dos limites sociais do crescimento, começando por eliminar gradualmente os resultados da sua negligência, nomeadamente a frustração de expectativas e o desperdício de recursos.

O reconhecimento dos limites permitirá a tomada de consciência em relação à sua existência e seus efeitos, por um lado, e a negociação de outros limites sociais com os quais a sociedade terá de aprender a conviver, por outro lado. A busca por uma participação mais abrangente torna a sociedade mais dependente de uma orientação colectiva para o recuo dos limites criados pelo próprio desenvolvimento do crescimento económico, através de um mecanismo da organização social que transmita às acções individuais as mudanças nas necessidades sociais, ou seja, meios colectivos para implementar fins individuais.

\section{Cesaltina Abreu}

Doutorada em Sociologia (2006) e mestre (2001) pelo Instituto Universitário de Pesquisas do Rio de Janeiro (IUPERJ), República Federativa do Brasil. É licenciada em Agronomia (1977) pela Universidade de Luanda (curso superior de Agronomia, Huambo). A sua dissertação de mestrado intitula-se Participação faz diferença? Reflexões na avaliação do Fundo de Apoio Social (FAS) no sudoeste de Angola (Huíla, Namibe e Kunene), e a tese de doutoramento tratou da Sociedade civil em Angola. Da realidade à utopia. Obteve o Certificado em estudos avançados em prática académica (CASAP), Módulos 1 e 2, na Universidade de Newcastle (2013), Grã Bretanha. É actualmente Professora Auxiliar e Chefe do Departamento de Sociologia da Faculdade de Ciências Sociais (FCS) da Universidade Agostinho Neto (UAN) e docente convidada do Curso de 
Mestrado em Ordenamento e Planeamento de Áreas Urbanas do Departamento de Arquitectura da Faculdade de Engenharia da UAN.

As suas áreas de interesse no âmbito da Sociologia Política envolvem questões multidimensionais da cidadania, análise de contexto, abordagens de «desenvolvimento», sustentabilidade e ambiente, capital humano e social, participação, direitos humanos e justiça social, cultura cívica, espaço público e sociedade civil, memória social, confiança e tolerância. Publicou, entre outros, os materiais seguintes: a) Livro: $A$ actualidade do pensamento de Alexis de Tocqueville na tensão entre igualdade e liberdade e entre indivíduo e sociedade nos processos de democratização contenporâneos (Luanda, Edições Mulemba; Ramada, Edições Pedago, 2015/2016, 110p. [«Cadernos de Ciências Sociais: Série Sociologia»; 3]; b) Em capítulo de livros: «Cidadania e participação em Angola. Que papel para a sociedade civil?», in José Octávio Van-Dúnem e Boaventura de Sousa Santos (orgs.), Sociedade e Estado em construção: Desafios do direito e da democracia em Angola. Luanda e justiça: Pluralismo jurídico numa sociedade em transformação, volume I, Coimbra, Almedina e CES - Centro de Estudos Sociais da Universidade de Coimbra, 2011, pp. 369-403; "Angola, SADC e a globalização», in Jonuel Gonçalves (org.), Atlântico Sul XXI. América do Sul e África na virada do milénio. São Paulo, Editora Unesp, pp. 185-207; «A sociedade civil em Angola e seus desafios internos e externos», in Nuno Vidal e Justino Pinto de Andrade, Sociedade civil e política em Angola. Enquadramento regional e internacional. Prefácio de Patrick Chabal. Luanda e Lisboa, Edições Firmamento e Média xxI, 2008, pp. 101-114; b) Artigos: «Pobreza em Angola: percepções, acção colectiva e os dilemas de participação com base numa pesquisa qualitativa» in Mulemba - Revista Angolana de Ciências Sociais (Luanda), vol. v, n. ${ }^{0}$ 9, Maio de 2015, pp. 319-344; «Para uma perspectiva sobre a prática das Ciências Sociais: uma leitura de Charles C. Ragin, Constructing social research: the unity and diversity of method», in Mulemba - Revista Angolana de Ciências Sociais (Luanda), vol. v, n. ${ }^{\circ}$ 9, Maio de 2015, pp. 525-555; "Globalização: Da transformação do espaço social à oportunidade de mudança social», in Mulemba - Revista Angolana de Ciências Sociais (Luanda), vol. Iv, n. ${ }^{\circ}$ 8, Novembro de 2014, pp. 391-420; «Revisitando uma obra exemplar: Dialectic of enlightenment. Philosophical fragments, de Theodor Adorno \& Max Horkheimer», in Mulemba - Revista Angolana de Ciências Sociais (Luanda), vol. Iv, n. ${ }^{\circ} 8$, Novembro de 2014, pp. 639-656; "Concepções e práticas pedagógicas no ensino das ciências sociais e humanas», in Mulemba - Revista Angolana de Ciências Sociais (Luanda), vol. Iv, n. ${ }^{\circ}$ 7, Maio de 2014, pp. 291-306 (em parceria com Eugénio da Silva e Pedro Manuel Patacho); «Em busca da (re)organização da vida em Angola», comunicação ao I Colóquio da Faculdade de Ciências Sociais da Universidade Agostinho Neto, Luanda, 25-26 Outubro de 2011, in Mulemba - Revista Angolana de Ciências Sociais (Luanda), vol. II, n. ${ }^{\circ}$ 3, Maio de 2012, pp. 103-127; «Desigualdade social e pobreza: 
ontem, hoje e (que) amanhã?», RAS - Revista Angolana de Sociologia (Luanda), n. ${ }^{\circ}$ 9, Junho de 2012, pp. 93-111.

[e-mail: tinaabreu@yahoo.com.br]

[e-mail: tinaabreu@hotmail.com] 